\title{
A NATUREZA SOCIAL DA PESSOA HUMANA
}

\author{
Antonio Wardison C. Silva* \\ Delmiro Vieira N. Junior**
}

\begin{abstract}
RESUMO
O presente texto desenvolve uma abordagem sobre a natureza social da pessoa humana a partir do seu valor e dignidade, segundo o pensamento filosófico-teológico de João Paulo II. Nesta perspectiva, se discute o valor inviolável da pessoa, dentro de um contexto cristão em íntima relação com a vida social e cultural do mundo contemporâneo. Para tanto o texto estrutura-se em três partes: o valor incomparável da vida e da pessoa humana; o desenvolvimento humano autêntico no panorama do mundo contemporâneo; e a ética cristã da pessoa humana. Em suma, o ser pessoa é um ser em devir, na história e na sociedade. Seus valores marcam sua natureza e, por isso, abre-se para a transcendência e para o relacionamento com o outro, na tentativa de mútuo reconhecimento, respeito e direcionamento para o fim último das coisas.
\end{abstract}

Palavras-chave: pessoa humana, dignidade, valor, natureza, social.

\begin{abstract}
This paper develops an approach to the social nature of the human person from its value and dignity, according to the philosophical and theological thought of John Paul II. From this perspective, discusses the inviolable value of the person, within a Christian context, in close relation with the social and cultural life of the contemporary world. For both the text is structured in three parts: the incomparable value of human life and human person, the authentic human development in the panorama of the contemporary world, and Christian ethics of the human person. In short, being a person, a being to become, in history and society. Their values characterize its nature and therefore open to transcendence and the relationship with the other, trying to mutual recognition, respect and guidance to the ultimate end of things.
\end{abstract}

Keywords: human person, dignity, value, nature, social.

Salesiano, licenciado em Filosofia, especialista em Filosofia Existencial e em Psicopedagogia, bacharelando em Teologia pelo Centro Universitário Salesiano de São Paulo - UNISAL, bolsista de IC pela Fundação de Amparo à Pesquisa do Estado de São Paulo - FAPESP.

** Salesiano, licenciado em Filosofia, bacharelando em Teologia pelo Centro Universitário Salesiano de São Paulo - UNISAL, e especialista em Catequese pelo mesmo Instituto. 


\section{INTRODUÇÃO}

Ao falar da pessoa humana, o ensinamento social de João Paulo II se abre para uma realidade singular que a caracteriza como tal. $O$ fato de que a pessoa humana se organiza em grupos por sua própria escolha é um ato de liberdade para o qual, naturalmente, todos os seres humanos são intencionados.

Desde o nascimento a pessoa humana é inserida num grupo social. $\mathrm{O}$ primeiro deles, sem dúvida nenhuma, é a família, que desempenha o papel de formar e educar a criança para a convivência de um grupo social maior.

A pessoa humana tem necessidade de vida social. Não é algo que lhe é acrescentado, mas próprio da sua natureza. Mediante o intercâmbio de relacionamentos com os outros, a reciprocidade de serviços e o diálogo com as outras pessoas, ela desenvolve as suas possibilidades naturais, as quais se tornam práticas que fazem dela um ser cada vez mais valorizado na sua dignidade. Pois "o homem sente a exigência imprescindível de encontrar-se em relação com os outros seres da sua própria espécie e sente satisfação particular quando consegue realizar essa disposição".

A sociedade se define pelo seu fim, mas a pessoa humana deve ser: princípio, sujeito e fim de todas as instituições sociais. Assim, a sociedade como um todo dá possibilidades para que cada pessoa, na sua individualidade, possa se desenvolver e se tornar parte integrante do meio social pela sua inserção e participação no que diz respeito aos seus interesses pessoais e ao bem comum. Essa maior participação é chamada de sociabilização e exprime a tendência natural dos seres humanos de se associarem para atingir objetivos que ultrapassam as capacidades individuais. A vida em sociedade desenvolve nas pessoas o espírito de iniciativa e de responsabilidade e ajuda garantir os direitos que podem ser violados pelos próprios responsáveis dotados de autoridade constituída.

A sociedade é indispensável à realização da vocação humana. Ora, a pessoa humana tende sempre à perfeição, à realização de suas possibilidades e ao encontro com o Bem. Neste sentido, a sociedade tem a tarefa de possibilitar a realização da vocação da pessoa: a plenificação no Bem, na Verdade e na Liberdade. A caridade representa o maior mandamento social: respeito ao outro e aos seus direitos. Ela, fundamentalmente, exige

1 Cf. MONDIN, B. O homem, quem é ele, p. 159. 
a prática da justiça. Por isso, inspira uma vida de autodoação. Segundo Maritain, "como pessoa o homem é 'centro', de certa maneira, inexaurível de bondade e de ação, capaz de doar e doar-se e capaz de receber, não somente este ou aquele dom feito por outra pessoa, mas outro si mesmo como dom, outro si mesmo como doador". ${ }^{2}$

Deste modo, a discussão sobre a natureza social da pessoa humana, a partir do seu valor e dignidade, remete a uma reflexão da mensagem cristã sobre a vida humana e o valor incomparável da pessoa, o desenvolvimento humano diante da cultura contemporânea e uma ética centrada na pessoa humana.

\section{O VALOR INCOMPARÁVEL DA VIDA E DA PESSOA HUMANA}

Uma das propriedades mais fundamentais e evidentes do ser humano é a vida. ${ }^{3}$ Ela surge como um mistério, particularmente, como um acontecimento que vai sendo percebido, singularizado, carregado de traços específicos, de experiências que marcam o processo de desenvolvimento de cada pessoa na sua individualidade.

O estudo do fenômeno da vida reveste-se de especial interesse por parte do homem. Pois a vida humana é uma forma de existência no mundo, a qual é caracterizada pela capacidade de automovimentar-se, de desenvolver-se, de reproduzir-se e de defender-se.

No pensamento filosófico cristão, a vida humana encontra uma posição de grande respeito e consideração, pois, conforme diz João Paulo II, "o homem é chamado a uma plenitude de vida que se estende para muito além das dimensões da sua existência terrena, porque consiste na própria vida de Deus". ${ }^{4}$ A sublimidade dessa vocação sobrenatural revela o valor e a grandeza preciosa da vida humana. A vida, na mensagem neotestamentária, encontra-se nos fundamentos do anúncio do ensinamento social cristão. A vida é a condição de possibilidade para que o ser humano, no decorrer de sua história, possa se realizar como pessoa chamada a uma vocação específica, que é a realização de si em comunhão com o seu Criador e com os outros.

2 Cf. MARITAIN, J. La persona e il bene comune. In: MONDIN, B. O homem quem é ele. Morcelliana: Bréscia, p. 169.

3 Cf. MONDIN, B. O homem, quem é ele, p. 43.

4 Cf. JOÃO PAULO II. Carta encíclica Evangelium Vitae, n. 2. 
O ensinamento cristão percebe a vida humana não como uma realidade última, mas penúltima. Trata-se de uma realidade sagrada confiada ao homem. O ser humano tem o direito à vida. Por isso a conivência humana e a própria comunidade política devem estar direcionadas para garantir e respeitar esse direito como bem primário. ${ }^{5}$ Dessa maneira, afirma João Paulo II, "o Evangelho do amor de Deus pelo homem, o Evangelho da dignidade da pessoa e o Evangelho da vida são um único e indivisível Evangelho". ${ }^{6}$

Na cultura contemporânea, a vida humana encontra-se ameaçada por inúmeros males que causam o distanciamento do seu fim último. O direito de vida e de subsistência deve ser subsidiado pela sociedade, na tentativa de garantir, a todos, possibilidade de desenvolvimento. Mas, em muitas situações, são encontradas condições de vida que estão abaixo do nível das necessidades básicas. A busca de valores de liberdade, que não reverenciam a vida em primeiro plano, pode levar as pessoas aos mais diversos crimes contra os seus semelhantes, principalmente os mais indefesos, como as crianças e os idosos.

Uma das características marcantes da modernidade é o desejo de autonomia, de participação da vida social, de garantia dos seus direitos individuais, de liberdade de escolha e de decisões que sejam livres de padrões que as regulamentem. A valorização da pessoa humana, no seu contexto de vida, é importante para que o indivíduo possa se caracterizar como pessoa única no seu contexto ontológico. Vale ainda ressaltar que na sua perspectiva ética a pessoa é um ser que vive em sociedade e que dela depende para a sua própria subsistência.

O ser humano pode criar uma cultura do individualismo que deturpa todo sentido personalista da filosofia. Muitas outras mazelas sociais são ocasionadas por concepções individualistas que não permitem um desenvolvimento humano na sua dimensão histórica e cultural. Por conseguinte, os frutos de tais tomadas de posição poderão tornar-se um obstáculo para a sua realização pessoal, como ser que tende à plena realização das suas potencialidades e da participação plena no Ser Absoluto e da plena felicidade que o ser humano está sempre buscando.

\footnotetext{
lbid., n. 2.

6 Ibid., n. 2.
}

108 Revista de Cultura Teológica - v. 18 - n. 71 - JUL/SET 2010 
As relações que o homem desenvolve, especificamente com as pessoas que estão próximas, tornam-se significativas de acordo com o valor que a elas se concede. Ao contrário, a evolução tecnológica e científica está provocando um afastamento entre as pessoas. Os meios de comunicação social tornam-se impessoais e buscam, dessa forma, atingir um número sempre maior de consciências. O ser humano é impulsionado pelo fazer, pelo tempo que não espera, pelo mercado de trabalho que seleciona os melhores, pelas relações de interesse que estão sendo cada vez mais difundidas entre os grupos pequenos, nos quais o contato é mais próximo:

Não só as relações pessoais vêm sendo transformadas com o desenvolvimento da humanidade, mas também a própria relação que cada pessoa trata consigo mesma. Em muitas ocasiões, hoje em dia, a própria pessoa não se valoriza. O corpo deixou de ser o espaço sagrado da manifestação de cada pessoa na existência, para ser objeto das satisfações egoísticas do ser humano. Como consequência do pecado, é perceptível uma perda considerável da própria atitude e tomada de posição por parte do ser humano em relação ao projeto de Deus, aos valores morais e éticos e em relação à sua própria dignidade e vocação. A relação consigo torna-se, numa cultura secularizada, a expressão de uma "mentalidade carnal", ou seja, uma "cultura carnal". A dimensão imanente do ser humano torna-se pressuposto reflexivo do problema antropológico e se coloca, muitas vezes, como uma barreira prática, mas, principalmente, conceitual no imaginário das pessoas. Esta é uma das manifestações de uma existência que aos poucos nega a dimensão transcendente do ser humano e a relação com o Transcendente, que é o próprio Deus.

Como outra grande consequência da negação da dimensão transcendente do ser humano apresenta-se a mudança de valores que são essenciais, condutas éticas e normas morais que organizam a vida social e possibilitam ao ser humano alcançar o seu fim último: a própria realização, enquanto pessoa, das potencialidades e da vocação à felicidade perfeita na comunhão com o seu Criador. Não existe nada que o homem produza nas suas relações com o cosmo que não seja transformado, modificado e adequado às necessidades da sua própria existência. $O$ próprio ser humano está em contínua transformação, está continuamente se desenvolvendo, tornando-se 
cada vez mais pessoa, mais ser humano. É nessa interação, entre as pessoas, que vai atingindo a sua maturidade natural, a própria construção de si, em comunidade, para participar do bem comum.

Dentre todas as ameaças possíveis contra a vida humana, pode ser ressaltada a indiferença do próprio ser humano em relação a tantos outros semelhantes que sofrem, privados de uma vida digna e das condições de torná-la melhor. Quando o homem abandona o seu desejo de preservação da vida, revela, com essa atitude de indiferença perante a vida, um desvio da sua própria natureza humana. Pois "o homem não está de forma alguma predestinado para o mal". ${ }^{7}$ O problema contemporâneo da recusa de responsabilidade pelo outro se torna um problema social, como aponta João Paulo II:

Saltam espontaneamente ao pensamento as tendências atuais de sonegar a responsabilidade do homem pelo seu semelhante, de que são sintomas, entre outros, a falta de solidariedade com os membros mais débeis da sociedade - como os idosos, os doentes, os imigrantes, as crianças - e a indiferença que tantas vezes se registra nas relações entre os povos, mesmo quando estão em jogo valores fundamentais como a sobrevivência, a liberdade e a paz. ${ }^{8}$

As tendências atuais, de forma de pensamento utilitarista, sonegam a responsabilidade do homem pelo seu semelhante, ocasionando problemas sérios de relacionamento e que trazem consideráveis consequências para os indivíduos atingidos por tais posturas numa organização social. Como comenta João Paulo II, a falta de solidariedade é uma das bases dos problemas que dizem respeito à promoção e conservação da vida. Em nome de uma cultura individualista, o ser humano legitima atrocidades, principalmente contra os mais indefesos, contra aqueles que não têm possibilidade de tomar partido em situações nas quais são os mais prejudicados. A indiferença diante de problemas causa a perda total do sentido da vida e da existência do outro. Instaura-se, dessa forma, a luta pela sobrevivência. O ser humano vai perdendo a sua dimensão social fundada na razão e no bem comum. Por conseguinte, ele mesmo "coloca em risco" a sua própria dignidade de

\footnotetext{
Cf. JOÃO PAULO II. Carta encíclica Evangelium Vitae, n. 8.
}

8 Ibid., n. 8.

110 Revista de Cultura Teológica - v. 18 - n. 71 - JUL/SET 2010 
semelhança e imagem do Criador, que é Unidade Perfeita, no qual está a grandeza e realeza da pessoa humana na realização da plena comunhão da família humana, na totalidade do ser de Deus.

Os problemas e as mudanças de mentalidade podem ser percebidos na maneira como as pessoas se manifestam perante seus semelhantes. João Paulo II expressa, no ensinamento cristão, o paradoxo na questão da preservação da vida humana:

Deus confia o homem ao próprio homem. E é tendo em vista também tal entrega que Deus dá a cada homem a liberdade, que possui uma dimensão relacional essencial. Trata-se de um grande dom do Criador, quando posto como deve ser a serviço da pessoa e da sua realização mediante o dom de si e o acolhimento do outro; quando, pelo contrário, a liberdade é absolutizada em chave individualista, fica esvaziada do seu conteúdo originário e contestada na sua própria vocação e dignidade. ${ }^{9}$

Segundo João Paulo II, é necessário chegar ao coração do problema do homem contemporâneo: "o eclipse do sentido de Deus e do homem, típico de um contexto social e cultural dominado pelo secularismo". ${ }^{10}$ Ao perder o sentido de Deus, o ser humano também perde o sentido da sua própria existência e humanidade. Deste modo, a vida humana passa a ser "uma coisa", deixando o seu caráter transcendente de existir. A vida do ser humano é aberta ao transcendente e o coração humano, expressão do centro vital para os antigos, não se inquieta enquanto não repousar na totalidade do Bem que completa os anseios mais profundos de cada pessoa humana. A própria relação com a natureza sofre as consequências de tal situação na vida do homem, pois ela é vista não como a fonte de subsistência e de preservação da comunidade humana, mas reduzida ao material, sujeita a toda manipulação. ${ }^{11}$

Inevitavelmente, esta postura do ser humano para com a pessoa humana, e também para com Deus, gera na sociedade os problemas de inversão de valores. Os significados e sentidos da existência humana deixam de ser

Cf. JOÃO PAULO II. Carta encíclica Evangelium Vitae, n. 19.

10 Ibid., n. 21.

11 Ibid., n. 22. 
valores transcendentais. Dá espaço a uma concepção axiológica referente à vida humana "dos valores do ser substituído pelos valores do ter". Escreve João Paulo II:

O critério próprio da dignidade pessoal isto é, o do respeito, do altruísmo e do serviço - é substituído pelo critério da eficiência, do funcional e da utilidade: o outro é apreciado não por aquilo que é, mas por aquilo que "tem, faz e rende". É a supremacia do mais forte sobre o mais fraco. ${ }^{12}$

Em nossos dias, mais do que nunca, fala-se em garantia de vida para as pessoas. A sociedade e principalmente os órgãos públicos devem garantir tais direitos: habitação, trabalho, lazer, estudo, saneamento básico e tantas outras formas que garantam a vida digna para o ser humano. As leis civis trazem nas suas deliberações posicionamentos que olham com atenção para a preservação e garantia da vida das pessoas que compõem a sociedade, pois a pessoa humana deve ser o fim de todas as instituições sociais.

Descendo às consequências práticas e mais urgentes, o Concilio Vaticano II insiste no respeito ao homem e afirma "que cada um respeite o próximo como 'outro eu', sem excetuar nenhum, levando em consideração antes de tudo a sua vida e os meios necessários para mantê-la dignamente". ${ }^{13}$ Por isso, o que atenta contra a vida, tudo o que viola a integridade da pessoa humana e tudo que ofende a dignidade humana, é efetivamente digno de censura porque contradiz a honra do Criador. "Assim, chega ao seu auge a verdade cristã acerca da vida. A dignidade desta não está ligada apenas às suas origens, à sua proveniência de Deus, mas também ao seu fim, ao seu destino de comunhão com Deus no conhecimento e no amor dele".14 Dessa forma, tendo por base a tradição antropológica cristã, João Paulo II expressa o valor incomparável da vida humana, da sua sacralidade e do cuidado e respeito que cada homem deve manifestar como uma lei moral inscrita na interioridade da pessoa humana.

Nesses traços marcantes é que percebemos onde a pessoa humana está inserida, vive e se desenvolve. A cultura não é algo temido, mas transformado pelo ser humano. No entanto, a cultura se apresenta, em alguns

12 JOÃO PAULO II. Carta encíclica Evangelium Vitae, n. 23.

13 Ibid., n. 27.

14 Ibid., n. 38.

112 Revista de Cultura Teológica - v. 18 - n. 71 - JUL/SET 2010 
de seus traços, como uma "cultura de morte". Em contrapartida, o Concílio Vaticano II vai dizer insistentemente que o cristão, ou como dizem muitos documentos eclesiais os "homens de boa vontade", é o primeiro responsável pela instauração de uma "cultura de vida" que, segundo João Paulo II, é a valorização da pessoa em toda a sua realidade e dimensões, para the garantir uma vida digna de pessoa humana.

Por isso, a preocupação com a realidade social seria o primeiro sinal no qual a atividade do filósofo poderia ser eficaz e responder às necessidades mais urgentes da pessoa humana. Deve-se considerar ainda que todo processo de maturação histórica, da humanidade, alcança seus objetivos, e responde a um diálogo com a cultura, quando o centro de toda a reflexão e a sua preocupação primeira é a pessoa humana em toda a sua dimensão existencial.

\section{O DESENVOLVIMENTO HUMANO AUTÊNTICO NO PANORAMA DO MUNDO CONTEMPORÂNEO}

"A solicitude social da Igreja, que tem como fim um desenvolvimento autêntico do homem e da sociedade que respeite e promova a pessoa humana em todas as suas dimensões, manifestou-se sempre das mais diversas maneiras." ${ }^{15} \mathrm{O}$ ensinamento social cristão, como toda tradição filosófica moderna, tem como centro de sua preocupação o homem nas suas mais variadas dimensões e no seu desenvolvimento integral. A sociedade não pode eximir-se da responsabilidade da solicitude pela pessoa humana e das suas necessidades mais básicas que lhe garantam a vida e a sobrevivência.

A comunidade humana percebe que, ao longo dos séculos, o desenvolvimento das técnicas e das ciências proporcionou, aos povos, uma qualidade melhor de existência. Porém, muitos ainda se encontram em condições deploráveis, de difícil acesso à qualidade de vida procurada por todo ser vivo como garantia de sobrevivência e de autorrealização. Assim, da preocupação social com "o desenvolvimento dos povos" surge a necessidade de uma concepção mais diferenciada do desenvolvimento. ${ }^{16}$

15 Cf. JOÃO PAULO II. Carta encíclica Solicitudo rei socialis, n. 1.

16 Cf. ibid., n. 4. 
A economia de uma sociedade gera riquezas para que a população possa ser beneficiada. Mas, por diversificados contextos históricos, as riquezas produzidas nem sempre chegam como benefício às mãos daqueles que trabalham. Não é difícil recordar o que aconteceu no Brasil e em tantos outros países da América espanhola: na colonização, o trabalho era baseado no tráfico de escravos que produzia riquezas adquiridas no país, como a exploração do ouro, produção de cana-de-açúcar e outras atividades de produção.

Neste período histórico, uma parcela pequena da sociedade saiu beneficiada. Outros (a maioria) não tiveram a oportunidade de se desenvolver como pessoas, pois seus direitos não foram valorizados. Os trabalhadores escravos não eram considerados como pessoas, mas sim como instrumentos de trabalho para o senhor dono da propriedade. Hoje, a atenção se volta de modo significativo para o problema social, pois na centralidade de toda reflexão filosófica, teológica e das ciências humanas e sociais, está a pessoa humana, que é enfocada segundo os métodos próprios de abordagem de cada ciência.

Ao comentar a encíclica Populorum Progressio de Paulo VI, João Paulo II aponta para o desenvolvimento da pessoa fundado no bem comum e na justiça:

Num mundo diverso, dominado pela solicitude do bem comum de toda a humanidade, ou seja, pela preocupação com o "desenvolvimento espiritual e humano de todos" e não com a busca do proveito particular, a paz seria possível como fruto de uma justiça mais perfeita entre os homens. ${ }^{17}$

João Paulo II aponta alguns dos problemas, chamando a atenção para uma retomada de posição diante das situações e condições em que se encontram tantas pessoas à procura não só da promoção humana e social, mas também da espiritual, que abre a possibilidade, no mais íntimo dessas pessoas, de ter esperança de melhoria na realidade em que se encontram. De fato, não se pode negar que muitas iniciativas religiosas, humanas, econômicas e técnicas não tenham sido vãs, uma vez que alguns avanços puderam ser alcançados. Mas, em linhas gerais, levando em conta os diversos fatores, não se pode negar que a situação atual do mundo, no aspecto do desenvolvimento, deixa uma impressão prevalentemente negativa. ${ }^{18}$

17 Cf. JOÃO PAULO II. Carta encíclica Solicitudo rei socialis, n. 10.

18 Cf. ibid., n. 13.

114 Revista de Cultura Teológica - v. 18 - n. 71 - JUL/SET 2010 
A primeira verificação negativa é o fosso entre os países do hemisfério norte desenvolvido e do sul subdesenvolvido (sem contar outros que estão em vias de desenvolvimento sem muitas condições de darem passos significativos para a melhoria da situação econômica e social). A preocupação com o desenvolvimento econômico faz com que não se olhe a pessoa como um todo, em sua dimensão cultural, religiosa e de lazer. Essa situação é fruto do crescente fenômeno da urbanização, que superlota as cidades e gera o surgimento de favelas nas zonas urbanas, sem condições de saneamento básico e de garantia de saúde para a população. O desemprego e as condições de subemprego, como também a dívida externa dos países pobres, são problemas que assolam a população e ocasionam os graves problemas sociais contemporâneos. ${ }^{19}$

Semelhante panorama da real situação do desenvolvimento no mundo contemporâneo não ficaria completo se não se notasse a coexistência de aspectos positivos: a primeira nota positiva é a da plena consciência de muitos homens e mulheres, da dignidade própria e da dignidade de cada ser humano. Essa tomada de consciência exprime-se na preocupação com os direitos humanos e na rejeição mais decidida de sua violação. Há de se reconhecer a influência exercida pela Declaração dos Direitos do Homem promulgada pela Organização das Nações Unidas. Há necessidade de uma solidariedade que assuma e traduza a Declaração dos Direitos do Homem no plano moral. Emerge progressivamente a ideia de que "o bem, ao qual todos somos chamados, e a felicidade, à qual aspiramos, não podem ser obtidas sem o esforço e a aplicação de todos, sem exceção, o que implica a renúncia ao próprio egoísmo". ${ }^{20}$ A solidariedade entre os povos é sinal do respeito pela vida, da promoção da paz, da não violência e da justiça, a consciência dos limites dos recursos naturais disponíveis e o respeito à integridade e aos ritmos da natureza. E, por fim, o empenho em remediar, com não poucos sacrifícios pessoais, os males do mundo para que homens e mulheres possam usufruir o benefício da paz e de uma qualidade de vida digna deste nome. ${ }^{21}$

Manter um desenvolvimento integral mais humano, sem negar as exigências econômicas, deve ser uma das condições para conservar a vocação

19 Cf. JOÃO PAULO II. Carta encíclica Solicitudo rei socialis, nn. 14-22.

20 Ibid., n. 26.

21 Ibid., n. 26.

Revista de Cultura Teológica - v. 18 - n. 71 - JUL/SET $201011 \mathbf{1 5}$ 
autêntica do homem. Para que de fato o desenvolvimento humano seja uma realidade, os bens da criação devem estar a serviço da pessoa humana. Segundo João Paulo II, jamais se pode esquecer a natureza específica do homem, criada por Deus:

Um desenvolvimento que não é só econômico mede-se e orienta-se segundo a realidade e a vocação do homem visto na sua globalidade; ou seja, segundo um parâmetro interior que lhe é próprio. O homem tem necessidade, sem dúvida, dos bens criados e dos produtos da indústria, continuamente enriquecida pelo progresso científico e tecnológico. E a disponibilidade sempre nova dos bens materiais, à medida que vem ao encontro das necessidades, abre novos horizontes. O perigo do abuso do consumo e o aparecimento das necessidades artificiais não devem, de modo algum, impedir a estima e a utilização de novos bens e de novos recursos postos à nossa disposição; devemos mesmo ver nisso um dom de Deus e uma resposta à vocação do homem, que se realiza plenamente em Cristo. ${ }^{22}$

O homem é o próprio protagonista do seu desenvolvimento. Dessa forma, é insustentável e defesa da cultura do ter sobre o ser. Apresenta-se como dever do homem colaborar no desenvolvimento integral dos outros, no "desenvolvimento do homem todo e de todos os homens". ${ }^{23}$ Ao contrário, hoje, no mundo contemporâneo, não se busca a realização da pessoa nos seus valores essenciais, mas busca-se satisfazê-la no domínio dos bens criados. Dessa maneira, o uso das coisas materiais se torna fim da direção da ação.

De outra forma, os bens materiais deveriam se tornar um meio para promover a pessoa humana. Cada ser humano assume como responsabilidade natural o comprometer-se com o seu próprio desenvolvimento em todas as suas dimensões, e a colaboração na promoção dos outros se torna até uma obrigação ética. Assim escreve João Paulo II, ao reafirmar a posição da encíclica Populorum Progressio de Paulo VI: "A colaboração para o desenvolvimento do homem todo e de todos os homens é, efetivamente, um dever de todos para com todos, e, ao mesmo tempo, há de ser comum às quatro partes do mundo". ${ }^{24}$

\footnotetext{
22 lbid., n. 29.

23 Cf. PAULO VI. Carta encíclica Populorum Progressio, n. 42.

24 JOÃO PAULO II. Carta encíclica Solicitudo rei socialis, n. 32.
}

116 Revista de Cultura Teológica - v. 18 - n. 71 - JUL/SET 2010 
Cada pessoa humana, como também cada povo, tem direito ao desenvolvimento integral. Não seria digno do homem um tipo de direito que não respeitasse e não promovesse os direitos humanos pessoais e sociais, econômicos e políticos, incluindo os direitos das nações e dos povos. A contradição intrínseca de um desenvolvimento limitado ao aspecto econômico subordina facilmente a pessoa humana e as suas necessidades mais profundas às exigências da planificação econômica ou ao lucro exclusivo. Por outro lado, a conexão intrínseca entre o desenvolvimento autêntico e o respeito dos direitos do homem revela uma vez mais o seu caráter moral: "A verdadeira elevação do homem, conforme a vocação natural e histórica de cada um, não se alcança só com o desfrute da abundância dos bens e dos serviços, ou dispondo de infraestruturas perfeitas". Para João Paulo II, os primeiros responsáveis, no âmbito político-social pela promoção da dignidade humana e sua respectiva promoção, são os dirigentes políticos, líderes sociais e os intelectuais e cientistas entre outros:

Um verdadeiro desenvolvimento, segundo as exigências próprias do ser humano, homem ou mulher, criança, adulto ou ancião, implica, sobretudo da parte de quantos intervêm ativamente neste processo e são responsáveis por ele, uma viva consciência do valor dos direitos de todos e de cada um, como também da necessidade de respeitar o direito de cada um à plena utilização dos benefícios proporcionados pela ciência e pela técnica. ${ }^{25}$

Sobre a relação do desenvolvimento da pessoa humana no uso da ciência e dos benefícios da técnica, Nogare se expressa dizendo que o "homem concreto não pode viver e realizar-se comunitariamente a não ser pelo trabalho técnico [...], [que] constitui o principal recurso de sobrevivência e desenvolvimento do homem". ${ }^{26}$ Para ser integral, o desenvolvimento deve realizar-se no quadro da solidariedade e da liberdade, sem sacrificar nenhuma delas. $O$ caráter moral do desenvolvimento e a necessidade da sua promoção são exaltados quando existe o mais rigoroso respeito por todas as exigências derivadas da ordem da verdade e do bem, próprios da criatura natureza.

\footnotetext{
25 Ibid., n. 33.

26 Cf. Nogare, P. D. Humanismos e antihumanismos, p. 217.
} 


\section{POR UMA ÉTICA CRISTÃ DA PESSOA HUMANA}

Segundo Marciano Vidal, ${ }^{27}$ "a pessoa realiza-se como sujeito se viver sua existência de uma forma conscientizada. A conscientização é uma forma de ser do homem. Essa instância tem que ser assumida dentro da ética cristã da pessoa". Ora, a pessoa humana é dotada de racionalidade, é capaz de ter consciência da existência das coisas, da sua própria existência e da existência de um Ser que Ihe confere a existência.

A conscientização é a assimilação de valores que a própria pessoa humana encarna nas suas relações: consigo mesma, com as outras pessoas e com o Transcendente. A consciência crítica abre as perspectivas da pessoa em relação à própria história. A pessoa é capaz de se colocar numa posição que lhe assegure a realização como pessoa, dotada de características que a tornam semelhante ao seu Criador e que the garantem a liberdade de direcionar os seus próprios atos. Como escreve Mounier, ${ }^{28}$ "a nossa liberdade é liberdade de pessoas situadas, e é também liberdade de pessoas valorizadas".

Pela consciência, a pessoa humana enraíza-se num contexto pessoal que a caracteriza como indivíduo singular aberto para a realidade social e comunitária, sendo essa uma vocação natural do ser humano. A pessoa humana é agente de construção e transformação do seu contexto social. É mediante a educação para a liberdade que o ser humano vai se descobrindo como pessoa, valoriza seu ser na sua integralidade ontológica e realiza ações de solicitude para com os seus semelhantes. Valorizar o homem na sua realidade pessoal é base de uma educação para a liberdade e responsabilidade sociais. Pois, "quem age para realizar o valor da pessoa, o desenvolvimento da pessoa e da sociedade age moralmente bem". ${ }^{29}$

Cabe aqui retornar às fontes nas quais João Paulo II fundamentou o seu discurso personalista e do qual pode ser destacado um pronunciamento sobre moral e ética, publicado em 1957: "A questão do sentido da vida humana guarda estreita relação com a questão da existência do homem e de tal existência em geral - uma autêntica filosofia da existência, por conseguinte, constitui o fundamento verdadeiro da ética". ${ }^{30}$

27 Cf. VIDAL, M. Moral de atitudes I, p. 135.

28 Cf. MOUNIER, E. O personalismo, p. 119.

29 Cf. MARCONETTI, L. Primeiros elementos de filosofia, p. 152.

30 Cf. WOJTYLA, K. Apud PADILHA, T. Conferência proferida no Congresso Internacional sobre Antropologia e Práxis no pensamento de João Paulo II, p. 11.

118 Revista de Cultura Teológica - v. 18 - n. 71 - JUL/SET 2010 
Um conceito que permeia o pensamento de João Paulo II é o conceito de experiência: ela está indubitavelmente relacionada com uma série de fatos, como algo dado. Entre esses dados compreende-se, a partir dos atos do homem, a totalidade dinâmica do homem. ${ }^{31}$

Ao analisar a pessoa, Wojtyla discerne, com maestria, os mundos exterior e interior, e aqui a interioridade ganha foros de cidadania metafísica: "A pessoa, diz ele, enquanto sujeito, distingue-se dos animais, mesmo os mais aprimorados, por sua interioridade, onde se encontra uma vida que Ihe é própria, sua vida interior". Ao partir desse pressuposto, de que a vida interior é a vida espiritual, Wojtyla abre espaço para uma integração autêntica do ser pessoa e dá dimensão plena a toda ação humana. A ação compreende o agir do homem em sua inteireza, enquanto a práxis é o que resta da ação, caso se faça a abstração de seu lado moral e de seu significado personalístico. Dessa maneira assim define o que é ação: "Se ação é [...] o momento especial da revelação da pessoa, isto quer dizer que não estamos interessados na ação enquanto conteúdo intencional constituído na consciência, senão que na realidade dinâmica que simultaneamente revela a pessoa enquanto sujeito eficaz". ${ }^{32}$

Na dimensão ética da pessoa humana é encontrada uma característica fundante na conceituação da realidade pessoal de cada ser humano. A dimensão intersubjetiva é a característica que engloba toda a atividade da relação humana. Pois a vocação do homem é a sua plena realização na comunhão com as pessoas. Por isso, as pessoas não podem ser tratadas como objetos, porque isso violenta o seu ser. Na relação interpessoal, a outra pessoa é sempre um "outro eu", ou seja, um outro sujeito no qual a relação acontece, e é a peça importante para que a dimensão social do homem responda à sua vocação e fim.

Principalmente na sociedade contemporânea, as dificuldades de fundar uma ética cristã da pessoa humana devem-se ao fato de existirem inúmeras correntes de pensamento que, de alguma forma, querem promover a pessoa, esquecendo-se de sua dimensão intersubjetiva e transcendente. Nesta perspectiva, João Paulo II defende uma ética da pessoa fundada no seu valor social e dirige seu pensamento na valorização das pessoas e da própria garantia de vida digna que realize cada ser humano em todas as suas

\footnotetext{
31 Cf. PADILHA, T. Conferência proferida no Congresso Internacional sobre Antropologia e Práxis no pensamento de João Paulo II, p. 12.

32 Ibid., p. 13.
} 
dimensões. Dessa forma, "o homem não pode abdicar de sua realização, de sua plenitude (a sua felicidade), que é aproximar-se sempre mais do bem, do ser e do amor absoluto". ${ }^{33}$ Por isso, o homem é feito para o Absoluto.

João Paulo II vai dedicar toda uma encíclica para apresentar o problema social do trabalho humano. Dessa maneira ele funda uma ética social da pessoa humana no que diz respeito a uma característica própria do ser humano: o trabalho, cuja atividade é relacionada com a manutenção da própria vida e preenche a sua existência sobre a terra. O trabalho comporta em si uma marca particular do homem e da humanidade. É o sinalizador de uma pessoa que opera numa comunidade de pessoas e, em certo sentido, constitui a sua própria natureza. Assim afirma João Paulo II:

O homem deve submeter a terra, deve dominá-la, porque, como "imagem de Deus", é uma pessoa; isto é, um ser dotado de subjetividade, capaz de agir de maneira programada e racional, capaz de decidir por si mesmo e tendente a realizar-se a si mesmo. É como pessoa, pois, que o homem é sujeito do trabalho. É como pessoa que ele trabalha e realiza diversas ações que fazem parte do processo de trabalho; estas, independentemente do seu conteúdo objetivo, devem servir todas para a realização da sua humanidade e para o cumprimento da vocação a ser pessoa, que Ihe é própria em razão de sua própria humanidade. ${ }^{34}$

A atividade do trabalho humano, assim como toda ação da pessoa, tem como fim ela mesma. O homem é o sujeito do trabalho e de todas as relações éticas que envolvem o agir humano. A virtude da laboriosidade é algo que faculta ao homem tornar-se bom como homem. Na relação familiar, o trabalho constitui a base sobre a qual a vida familiar se fundamenta. Ele condiciona o processo de educação na família. Neste sentido, sustenta João Paulo II, "a família constitui um dos mais importantes termos de referência segundo os quais tem de ser formada a ordem sócio-ética do trabalho humano". ${ }^{35}$

O princípio fundamental de uma ética cristã centrada na pessoa é o de fazer o bem que gostaria que fosse feito a si, ou seja, o princípio da ação

\footnotetext{
MARCONETTI, L. Primeiros elementos de filosofia, p. 153.

34 Cf. JOÃO PAULO II. Carta encíclica Laborem exercens, saudação.

35 Ibid., n. 10.
}

120 Revista de Cultura Teológica - v. 18 - n. 71 - JUL/SET 2010 
é o sujeito que age, mas o fim é o outro que recebe a ação produzida por um único indivíduo.

A lei divina ou natural mostra ao homem o caminho a seguir para praticar o bem e atingir seu fim. A lei natural enuncia os preceitos primeiros e essenciais que regem a vida moral. Essa lei é natural não porque se relaciona à natureza, mas porque promulga algo próprio da natureza humana. Presente no coração de cada homem e estabelecida pela razão, a lei natural é universal em seus preceitos e sua autoridade estende-se a todos os homens. Ela exprime a dignidade da pessoa e determina a base de seus direitos e deveres.

A moralidade dos atos é definida pela relação da liberdade do homem com o bem autêntico. A ordenação racional do ato humano para o bem na sua verdade e a procura voluntária deste bem conhecido pela razão constituem a moralidade. $O$ agir é moralmente bom quando atesta e exprime a ordenação voluntária da pessoa para o seu fim último e a conformidade da ação concreta com o bem humano, pois cada ser tende para o seu fim. Essa lei é conhecida pela razão natural do homem. Isto quer dizer:

O agir é moralmente bom quando as escolhas da liberdade são conformes ao verdadeiro bem do homem e exprimem, desta forma, a ordenação voluntária da pessoa para o seu fim último, isto é, o próprio Deus: o bem supremo, no qual o homem encontra a sua finalidade plena e perfeita. ${ }^{36}$

Dessa maneira, se o objeto da ação concreta não está em sintonia com o verdadeiro bem da pessoa, a escolha de tal ação torna a vontade do homem e a ele próprio moralmente mau e, portanto, em contraste com o seu fim último, o bem supremo, isto é, o próprio Deus: "Quanto mais bondade, justiça social, amor, [eu] nós realizarmos, tanto mais, [eu] nós nos aproximaremos do Ser Absoluto: Deus". ${ }^{37}$

\section{CONCLUSÃO}

A reflexão filosófica, a partir da Modernidade, sempre teve como ponto de partida o ser humano. Nas suas mais variadas dimensões, o homem já

${ }_{37}$ Cf. JOÃO PAULO II. Carta encíclica Veritatis Explendor, n. 72.

37 Cf. Marconetti, L. Primeiros elementos de filosofia, p. 154.

Revista de Cultura Teológica - v. 18 - n. 71 - JUL/SET 2010121 
foi estudado, mas o assunto não se esgota devido à complexidade de uma análise antropológica acerca da pessoa humana, um mistério que se revela por si só. A filosofia tem como atividade perscrutar as causas primeiras e últimas da realidade. O homem - sujeito, objeto e fenômeno de tal processo crítico e investigativo - coloca-se como centro de toda reflexão. Sendo assim, constrói paradigmas epistemo-filosóficos que discutem sua dignidade de pessoa humana.

Ao longo destes dois últimos séculos, o pensamento filosófico cristão vem discutindo, a partir do magistério apostólico, a questão antropológica: como o ser humano é encarado nas suas relações histórico-sociais. A antropologia filosófica muito contribui nessas reflexões, nos avanços práticos e na discussão do valor e dignidade da pessoa humana, particularmente por meio da contribuição de vários autores da corrente personalista cristã (que dão fundamentação a um ensinamento humanista centrado na pessoa, seu valor e sua dignidade).

Nesta perspectiva, João Paulo II é o pensador que orienta, embasa e sustenta uma aprofundada reflexão sobre a dignidade da pessoa humana. Ele, desde jovem, interessou-se pelos estudos filosóficos orientados pela produção científica da corrente personalista de Emmanuel Mounier (19051950), originária da França. Dentre os inúmeros escritos de João Paulo II, têm-se como base as encíclicas produzidas nos seus vinte e seis anos de pontificado: Redemptor Hominis, Laborem Exercens, Solicitudo Rei Sicialis, Centesimus Annus, Veritatis Splendor e Evangelium Vitae.

A encíclica Redemptor Hominis apresenta o ser humano como centro e construtor da história pessoal e dos fundamentos da dignidade humana; as encíclicas Laborem Exercens, Solicitudo Rei Sicialis e Centesimus Annus tratam da pessoa humana na sua relação social e do seu desenvolvimento na sociedade. As encíclicas Veritatis Splendor e Evangelium Vitae tratam, respectivamente, dos principais problemas morais e éticos da contemporaneidade e do valor e inviolabilidade da vida humana.

Dessa maneira evidencia-se que, na contemporaneidade, a discussão sobre a dignidade da pessoa humana torna-se necessária, principalmente diante das tendências mecanicistas e pragmatistas existentes, hoje, no seio da sociedade econômica.

Por isso, este ensaio, baseando-se na dimensão social da pessoa humana, a partir do seu valor e dignidade, segundo o ensinamento

122 Revista de Cultura Teológica - v. 18 - n. 71 - JUL/SET 2010 
antropológico-social delineado por João Paulo II, propõe uma reflexão sobre o valor e inviolabilidade da vida humana, o seu desenvolvimento autêntico no panorama do mundo contemporâneo e uma ética centrada na pessoa humana em suas relações sociais. Torna-se uma vertente do horizonte da corrente personalista cristã para conhecer e respeitar cada pessoa humana na sua dignidade transcendental, na realização da sua vocação pessoal e fim último.

\section{REFERÊNCIAS BIBLIOGRÁFICAS}

JOÃO PAULO II. Carta encíclica Evangelium vitae (25-03-1995). São Paulo: Paulus, 1997. (Col. Doc. da Igreja). . Carta encíclica Laborem exercens, saudação (15-09-1981). São Paulo: Paulus, 1997. (Col. Doc. da Igreja).

. Carta encíclica Solicitudo rei socialis (30-12-1987). São Paulo: Paulus, 1997. (Col. Doc. da Igreja).

. Carta encíclica Veritatis explendor (06-08-1993). São Paulo: Paulus, 1997.

(Col. Doc. da Igreja).

MARCONETTI, L. Primeiros elementos de filosofia. Campo Grande: UCDB, 2003.

MARITAIN, J. La persona e il bene comune. Morcelliana: Brescia, 1963.

MONDIN, B. O homem quem é ele? Elementos de antropologia filosófica. São Paulo: Paulus, 2003.

MOUNIER, E. O personalismo. Lisboa: Livraria Moraes Editora, 1964.

NOGARE, P. D. Humanismos e anti-humanismos: introdução à antropologia filosófica. 11. ed. Petrópolis: Vozes, 1988.

PADILHA, T. Conferência proferida no Congresso Internacional sobre Antropologia e Práxis no pensamento de João Paulo II. Rio de Janeiro, 18 a 22 de outubro de 1984.

PAULO VI. Carta encíclica Populorum Progressio (26-03-1967). São Paulo: Paulinas, 1978. (Col. A voz do Papa).

VIDAL, M. Moral de atitudes II: ética da pessoa. São Paulo: Santuário, 1981.

WOJTYLA, K. In: PADILHA, T. Conferência proferida no Congresso Internacional sobre Antropologia e Práxis no pensamento de João Paulo II. Rio de Janeiro, 18 a 22 de outubro de 1984 . 